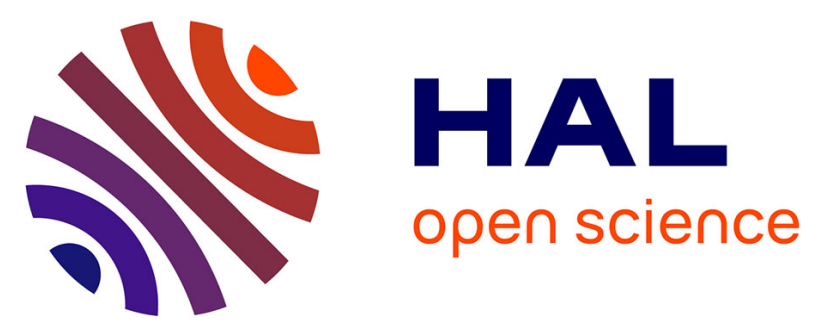

\title{
Size effect regarding fatigue evaluation of asphalt mixtures
}

Didier Bodin, Chantal de La Roche, Gilles Pijaudier-Cabot

\section{To cite this version:}

Didier Bodin, Chantal de La Roche, Gilles Pijaudier-Cabot. Size effect regarding fatigue evaluation of asphalt mixtures: Laboratory cantilever bending tests. Road Materials and Pavement Design, 2006, ASPHALT TECHNOLOGY (EATA 2006), 7 (Supp 1), pp.181-201. 10.1080/14680629.2006.9690064 . hal-00357740

\section{HAL Id: hal-00357740 \\ https://hal.science/hal-00357740}

Submitted on 1 Feb 2009

HAL is a multi-disciplinary open access archive for the deposit and dissemination of scientific research documents, whether they are published or not. The documents may come from teaching and research institutions in France or abroad, or from public or private research centers.
L'archive ouverte pluridisciplinaire HAL, est destinée au dépôt et à la diffusion de documents scientifiques de niveau recherche, publiés ou non, émanant des établissements d'enseignement et de recherche français ou étrangers, des laboratoires publics ou privés. 


\section{Size effect regarding fatigue evaluation of asphalt mixtures}

\section{Laboratory cantilever bending tests}

\section{Didier Bodin* - Chantal de La Roche* — Gilles Pijaudier-Cabot ${ }^{* *}$}

* Laboratoire Central des Ponts et Chaussées

Division Matériaux et Structures de Chaussées

Route de Bouaye, BP 4129, F-44341 Bouguenais Cedex

didier.bodin@lcpc.fr

chantal.de-la-roche@lcpc.fr

** École Centrale de Nantes R\&DO - GeM Institut de recherches en Génie Civil et Mécanique UMR 6183

Rue de la Noё - BP 92101, F-44321 Nantes Cedex 3

Gilles.Pijaudier-Cabot@ec-nantes.fr

ABSTRACT. EXperimental results for fatigue tests on three size geometrically similar asphalt concrete specimen are presented. Effect on fatigue life is analyzed and compared to trends given by a fatigue damage model. This innovative laboratory campaign points out a size effect on fatigue assessment of asphalt mixture. In a second part, the application of a nonlocal fatigue damage model for asphalt mixtures is presented. A qualitative agreement is obtained between experimental results and non local damage fatigue predictions trends. This agreement validates the nonlocal modelling that allows to model the influence of the heterogeneous nature of the material on fatigue failure. Differences observed between laboratory data and model predictions may be attributed to viscoelasticity induced thermal softening which had to be quantified and coupled to damage in order to properly study these fatigue test data.

KEYWORDS. asphalt mixture, fatigue, performance evaluation, size effect, laboratory, damage model. 


\section{Introduction}

It has been shown for a while that, for a given material, the strength depends on the specimen size (da Vinci, 1881-91; Galileo, 1638). Consequently, strength is no longer a material constant. Such a phenomenon is called size effect. Size effects on both strength and fracture toughness of structural materials have been experimentally observed on different materials such as cement concrete, rocks, composite materials, ice, .... As an example, tensile strength and fatigue strength decrease with the specimen size (Bažant, 2002). Commonly, scaling law parameters are determined by fitting models on experimental data. Size effect on material strength under static loading has extensively been analyzed during the last few decades, and several theories have been proposed. However, only few examples exist for cyclic and fatigue loading on cement concrete (Bažant et al., 1991).

Concerning asphalt mixtures in fatigue, the influence of the tested specimen shape has been highlighted in the literature (SHRP, 1994; de La Roche, 1996; Benedetto et al., 2003) but few results are available on specimen with the same shape but different sizes called "homothetic" or geometrically similar specimens. In order to explore the influence of the specimen size vs the size of aggregates, Doan (Doan, 1973) made a study on one loading level for a $0 / 20 \mathrm{~mm}$ asphalt mixe on quasi geometrically similar trapezoidal specimen of two sizes(30 samples : height $250 \mathrm{~mm}$ large base $56 \mathrm{~mm}$, small base $25 \mathrm{~mm}$ and thickness $25 \mathrm{~mm}$ approximatly conform to the present european standard) and a bigger size (10 samples: height $500 \mathrm{~mm}$, large base $90 \mathrm{~mm}$, small base $30 \mathrm{~mm}$ and thickness $30 \mathrm{~mm}$ ). For a low loading level, he concluded that the specimen size effect was neglectible leading to the same average fatigue life for each specimen series. However, more extensive studies are necessary to separate size and scattering effects.

This paper presents an experimental campaign performed on different specimen sizes on bending fatigue tests derived from the so-called "two points" bending fatigue test on trapezoidal specimens (NF EN 12697-24). Three size are considered leading to three similar specimen series.

Elaboration of the specimens, material and specimen characteristics are presented in section 2. Then fatigue results analyzis and classical fatigue life interpretation are performed in order to evaluate the size effect on fatigue performance evaluation. Experimental trends are then compared to theoretical results given by a non local fatigue damage model (Bodin et al., 2004b; Bodin, 2002). The good qualitative agreements obtained are investigated in further details with the trends expected from viscoelasticity induced self heating of the thermal dependant material specimens.

\section{Specimen fabrication and material characterization}

The material used for this study is a $0 / 6 \mathrm{~mm}$ dense asphalt concrete containing $6.4 \%$ of $50 / 70$ pure bitumen detailed in Table 1 . 
Table 1. Composition and grading curve of the tested material

\begin{tabular}{cccccccccc}
\hline \multicolumn{1}{c}{ Grading [\% passing] } & \multicolumn{3}{c}{ Binder } \\
\hline sieve & 0.08 & 0.315 & 1 & 2 & 4 & 6.3 & 8 & Type & $50 / 70$ \\
BBC & 11.8 & 22.6 & 39 & 59.5 & 70.2 & 97 & 100 & Content \% & 6.4 \\
\hline
\end{tabular}

For the size effect study, specimens are 2D geometrically similar and their thickness is the same as it is shown in the table presented figure 1(b). Size 1.0 corresponds to the standardized size.

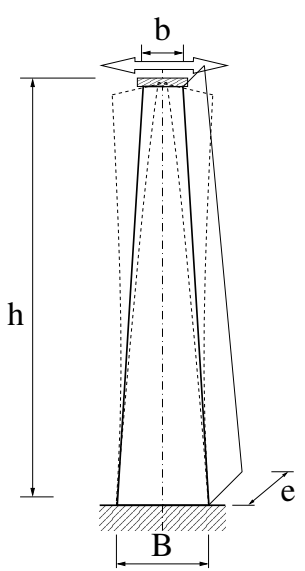

(a)

\begin{tabular}{ccccc}
\hline & \multicolumn{4}{c}{ Dimension [mm] } \\
Size & $\mathrm{h}$ & $\mathrm{B}$ & $\mathrm{b}$ & $\mathrm{e}$ \\
\hline $\mathbf{0 . 5}$ & 125 & 28 & 12.5 & 25 \\
$\mathbf{1}$ & 250 & 56 & 25 & 25 \\
$\mathbf{2}$ & 500 & 112 & 50 & 25 \\
\hline
\end{tabular}

(b)

Figure 1. Test principle (a) and dimensions of the tested specimens (b)

Mixtures were manufactured at LCPC and compacted in slabs using the LCPC rolling wheel compactor (NF EN 12697-33). The final dimensions of the slabs were $150 \times 400 \times 600 \mathrm{~mm}$. The sawing of the samples of different sizes had been done by transposition of the standardized method. Samples are sawn vertically and parallelly to the compaction direction, from the slabs compacted in the laboratory (figure 2).

The homogeneity of each different size set of samples has been compared in terms of average void content. For the $n$ tested samples, the void content mean value $\bar{V}_{a}$ and its standard deviation $\sigma_{V_{a}}$ have been calculated for each size. Results are presented figure 3.

Void content scattering decreases when the specimen size increases. This is quite understandable as small size specimens directly capture material heterogeneity whereas big size specimens allow an averaging of the mesostructure of the material. However, the average void contents between sample sets are very similar, varying of one percent. 


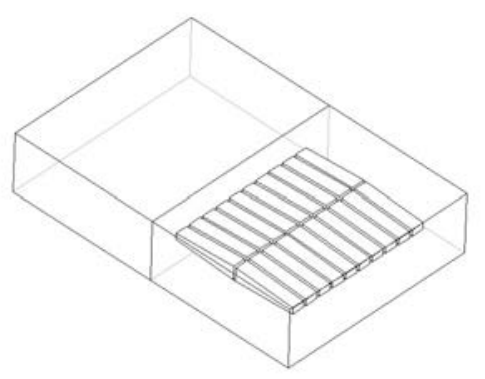

(a)

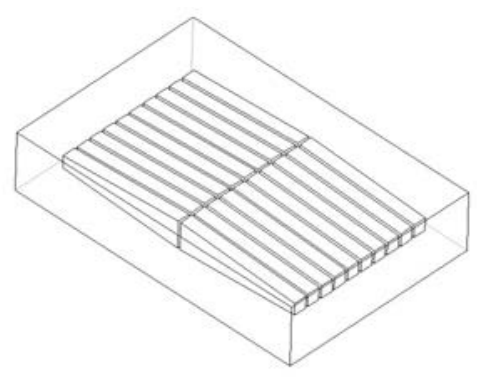

(b)

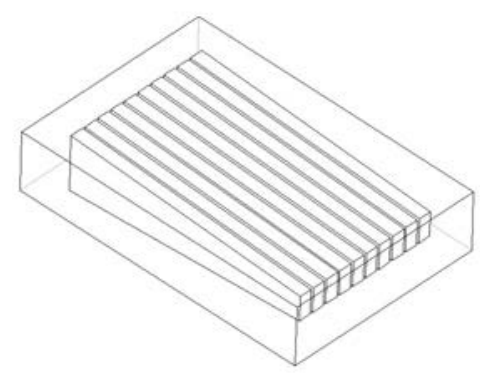

(c)

Figure 2. Specimen preparation procedure : (a) size 0.5, (b) size 1.0 and (c) size 2.0

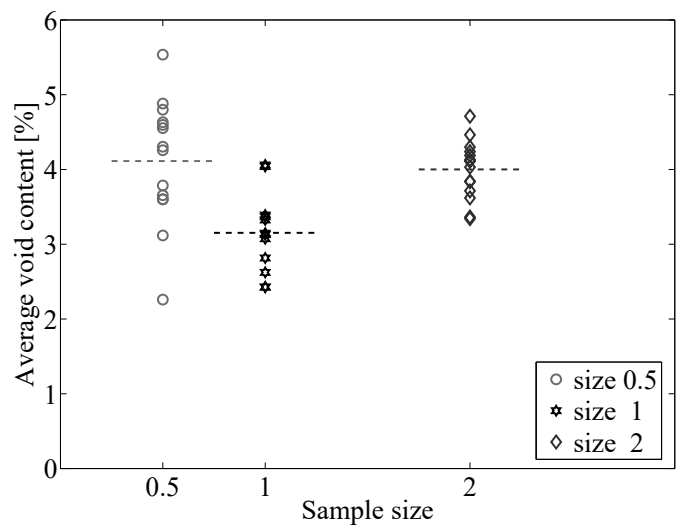

(a)

\begin{tabular}{lccc}
\hline & \multicolumn{3}{c}{ Size } \\
& 0.5 & 1 & 2 \\
\hline$n$ & 14 & 12 & 15 \\
$\bar{V}_{a}[\%]$ & 4.1 & 3.2 & 4.0 \\
$\sigma_{V_{a}}[\%]$ & 0.84 & 0.54 & 0.38 \\
\hline
\end{tabular}

(b)

Figure 3. Void content value (\% by volume) of each specimen for the different sizes

\section{Fatigue tests}

Fatigue tests consist in applying a sinusoidal displacement at the head of a cantilever trapezoidal beam (figure 1). The frequency is fixed to the value of $10 \mathrm{~Hz}$. Tests are performed in a thermal chamber controlling the temperature at a value of $10^{\circ} \mathrm{C}$. For each of the three size different series, at least four specimens have been tested for each loading level. Three loading strain levels have been tested $14010^{-6}, 18010^{-6}$ and $22010^{-6}$ leading to fatigue life between $510^{4}$ and $310^{6}$ cycles. These loading levels are equal to the maximal strain value in the specimen according to the classical beam theory.

During the test, force and displacement amplitude are recorded. The effective stiffness of the sample is calculated as the ratio of force amplitude to displacement amplitude. Then, the test result is plotted as the ratio of effective stiffness to initial stiffness versus the number of cycles. 


\subsection{Initial modulus}

During fatigue, initial modulus has been measured for each sample. Initial modulus values are compared in regards to the sample size. An important aspect is to verify the influence of loading amplitude at the beginning of fatigue test for each serie, i.e. the existence of non linearity since the beginning of fatigue test (Benedetto et al., 2003; Lundstrom et al., 2004).

Initial modulus measurements are plotted in figure 4(a) versus the loading level and presented in terms of their average values $\bar{E}_{0}$ and their standard deviation $\sigma_{E_{0}}$ for the $n$ samples tested of each serie figure 4(b).

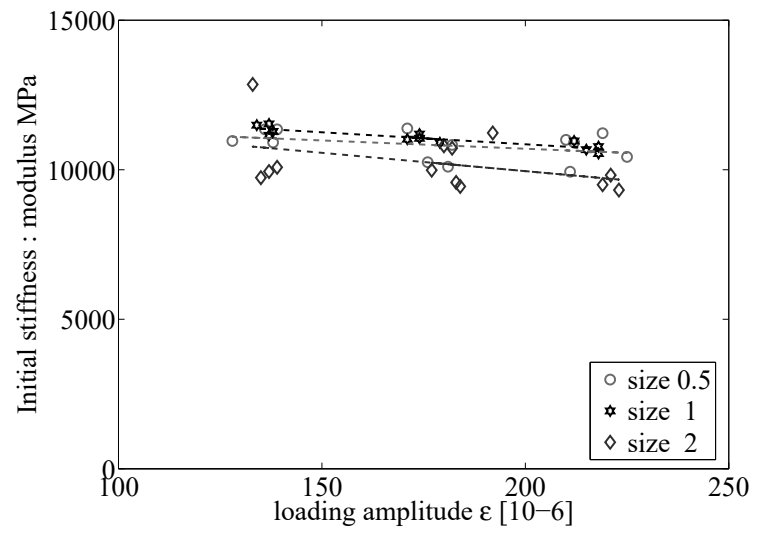

(a)

\begin{tabular}{lccc}
\hline & \multicolumn{3}{c}{ Size } \\
& 0.5 & 1 & 2 \\
\hline$n$ & 14 & 12 & 15 \\
$\bar{E}_{0}[\mathrm{MPa}]$ & 10770 & 11050 & 10280 \\
$\sigma_{E_{0}}[\mathrm{MPa}]$ & 498 & 305 & 954
\end{tabular}

(b)

Figure 4. Initial stiffness value function of the specimen size

The results obtained from the different sizes show that for each tested loading level, no significative difference can be found between the different sizes. In the tested loading range, initial stiffness does not depend on strain amplitude even if a light trend, corresponding to a classical decrease of modulus with the increase of the loading level, can be observed in the linear regression presented figure 4(a).

\subsection{Size effect on fatigue}

The size effect is first studied comparing the stiffness decrease plots. Then fatigue lifes for each sizes are compared and finally, size effect on Wöhler curves is presented to conclude on the classical fatigue performance evaluation using such kind of tests.

\subsubsection{Size effect on stiffness decrease}

For each test, the decrease of the effective stiffness is plotted as a function of the number of loading cycle. For the three loading levels, results are presented figure 5 . Typically, the stiffness decrease follows a three stage evolution process. The rapid drop at the early beginning is followed by a slowest decrease. The ultimate stage, 


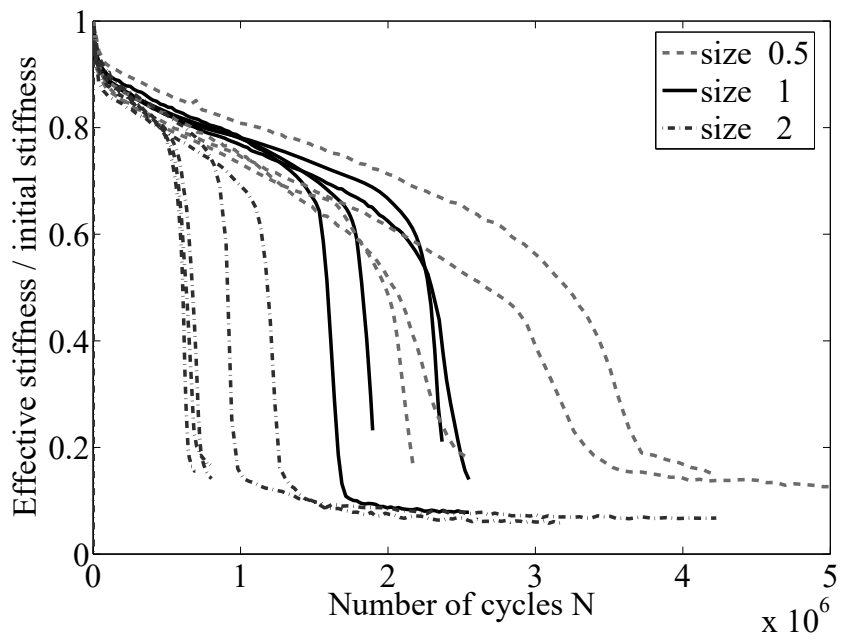

(a)

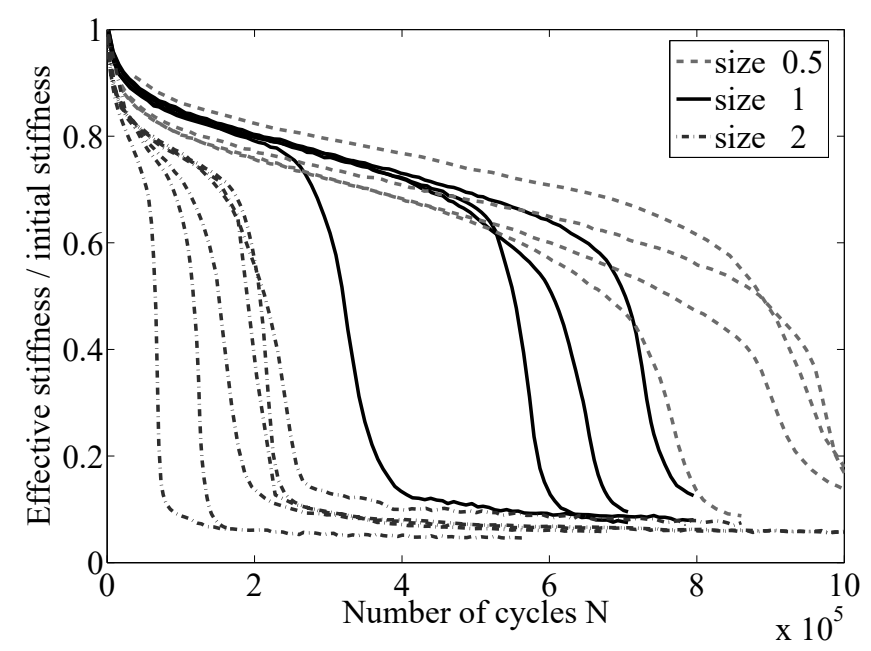

(b)

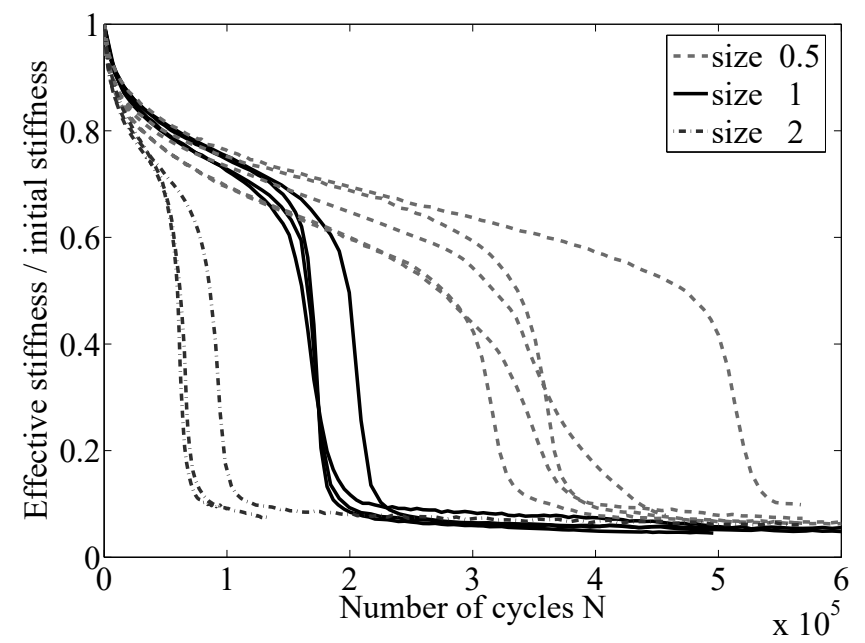

(c)

Figure 5. Global stiffness decrease during displacement controlled fatigue tests at $10^{\circ} \mathrm{C}-10 \mathrm{~Hz}$ for the three loading levels (a) $14010^{-6}$ (b) $18010^{-6}$ (c) $22010^{-6}$ 
leading to the specimen failure is characterized by an acceleration of the decrease rate.

First, it has to be pointed out, that the difference in void content (Fig. 3) has no significant effect on fatigue phenomenon and its effect is included in the general scatter of fatigue life. Then comparison can be done between the different specimen series.

On figure (5(c)) where the highest level $\left(22010^{-6}\right)$ tests are plotted, the different sets of different sizes are very clearly separated. The biggest the size, the shortest the fatigue life. This result is confirmed by figures $(5(\mathrm{a}), 5(\mathrm{~b}))$ for the lowest and medium level. For those conditions, the discrimination between the different series, exists too, even if the sizes 0.5 and 1.0 are less discriminative. Nevertheless, the effect of the size seems to be more important with the increasing of the loading level.

\subsubsection{Size effect on fatigue life}

The fatigue life of each specimen is fixed to the number of loading cycles leading to a $50 \%$ decrease of the sample stiffness.

Size effects are classically explored as the variation of a resistance parameter such as material failure stress. Concerning fatigue on notched specimen, the crack propagation speed is studied in terms of Paris law parameters (Carpinteri et al., 2004; Bažant et al., 1991). In our case dealing with the growth of a damaged zone from a smooth surface, size effects exist but no models are available in the literature. As a first approach for fatigue of asphalt mixture, we can explore the size effect on the number of cycles to failure (fatigue life) of each specimen. The fatigue life is a relevant indicator of the material resistance to fatigue but dependant on the loading level, so we will consider each loading level as an independent specimen set.

To do so, this size effect is investigated by plotting, for each loading level, the average logarithm of fatigue life versus the size (figure 6(a)).

This plot is another illustration of the decrease of the fatigue life with the size of the sample characterized before. To see if this size effect is dependant on the loading level, we propose to calculate the relative loss or profit in fatigue life for size 0.5 or size 2.0 by comparison to size 1.0 experiments. The fatigue life ratios function of the loading level are gathered in table (figure 6(b)).

For size 0.5 the ratio is greater than one, this means an increase of fatigue life from size 1.0 to size 0.5 . For these two sizes, the ratio appears to increase with the loading level but this trend is not confirmed by results from size 1.0 to size 2.0. Fatigue life decreases with the increasing of size as shown by the ratio which is smaller than one.

However, even if this point had not been presented in details in this study, as it was reported in (Bodin et al., 2004a) for tension compression fatigue tests, it is necessary to recall that self heating of the specimen due to viscoelastic dissipation occurs during fatigue tests and this phenomenum leads to a size effect which is superimposed and probably coupled to the intrinsic material one. 


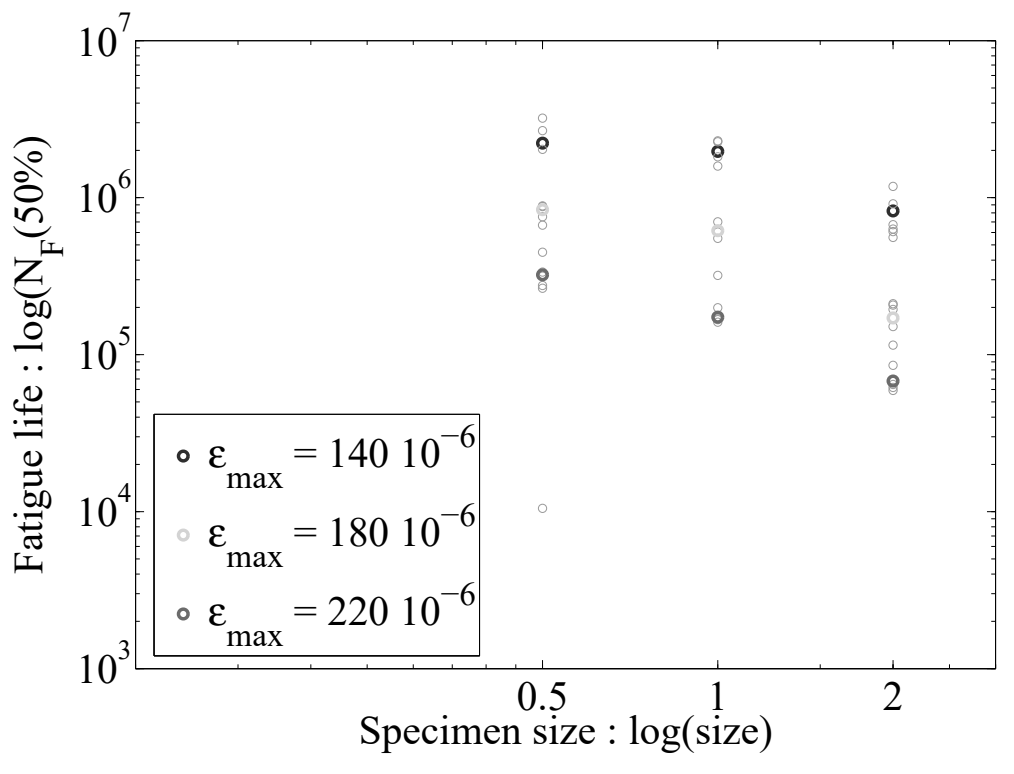

(a)

\begin{tabular}{lccc}
\hline level $\left[10^{-6}\right]$ & \multicolumn{3}{c}{ Size } \\
& 0.5 & 1 & 2 \\
\hline 140 & 1.1 & 1 & 0.42 \\
180 & 1.4 & 1 & 0.28 \\
220 & 1.9 & 1 & 0.39 \\
\hline
\end{tabular}

(b)

Figure 6. (a) Effect of the specimen size on the fatigue life - $N_{F}(50 \%)$ (b) ratio of fatigue life for each size $i$ to fatigue life for the reference size 1.0 for each loading levels

This last effect, leading to a material softening due to material temperature increase, is qualitatively in accordance with the increasing of the size effect with the increasing of the loading level observed between the sizes 1.0 and 0.5 .

To finalize the extensive study of size effect, the following section presents the effect of the size on the fatigue Wöhler curve and thus on fatigue performances of asphalt mixtures for pavement design.

\subsubsection{Size effect on Wöhler curve}

Wöhler curves consist in plotting the fatigue life versus the strain loading amplitude. It directly illustrates the effect of loading level on fatigue life. It can be reminded that fatigue life is defined by the number of cycles required to reach a $50 \%$ decrease of the normalized stiffness quoted $N_{F}(50 \%)$.

Concerning asphalt mixtures, classical fatigue models are based on a linear regression in a log-log diagram based on a fatigue law which can be presented according to the following equation :

$$
N_{F}(50 \%)=10^{6}\left(\frac{\varepsilon_{a}}{\varepsilon_{6}}\right)^{p}
$$

Where $p$ is the fatigue line slope, $\varepsilon_{6}$ the loading level leading to a fatigue life of $10^{6}$ cycles. This expression leads to a line in a log-log plot of fatigue life versus 
loading amplitude. With this expression (Eq. 1) the Wöhler curve is called the fatigue line. The fatigue line plots, for the different sizes, are presented figure 7(a).

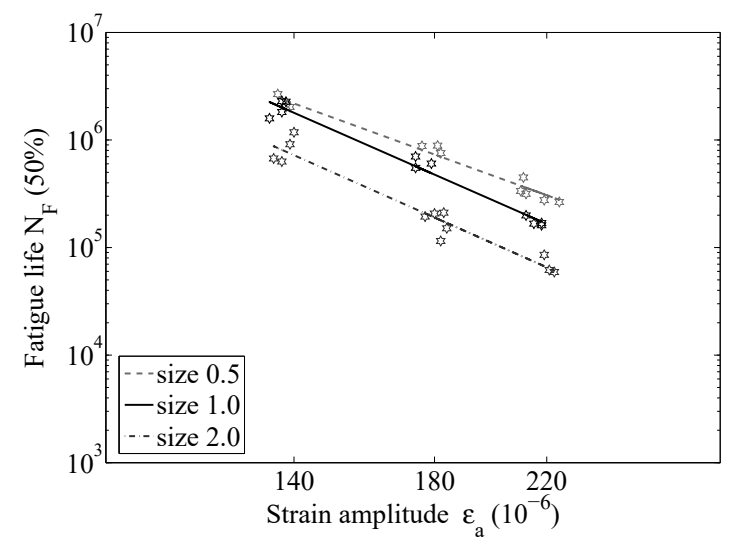

(a)

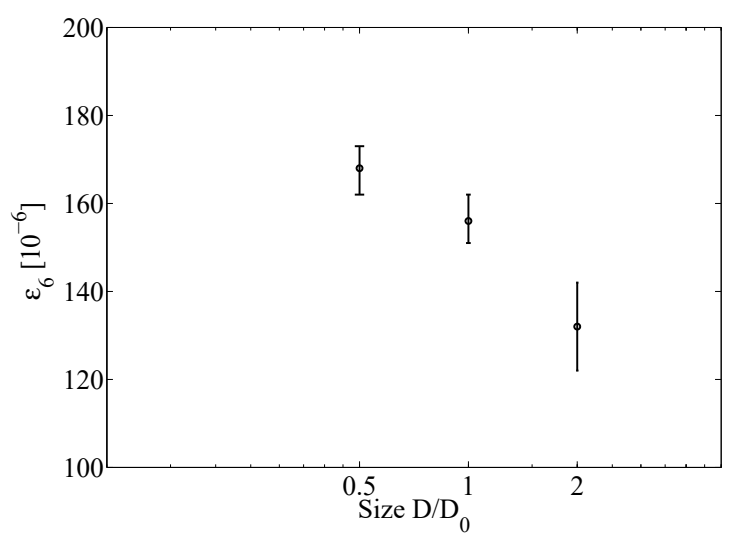

(b)

Figure 7. (a) Fatigue line fitted for each sample size - (b) Values and uncertainty of $\varepsilon_{6}$ versus the size of the specimen sets

The fatigue line parameters for the different sizes are gathered in the table presented below (Tab. 2). In order to compare the results, linear regression parameters are complemented with their confidence intervals calculated for a prediction $95 \%$ probability (Tomassone et al., 1992).

Table 2. Fatigue line parameters for each size sets

\begin{tabular}{cccc}
\hline size & 0.5 & 1 & 2 \\
\hline Slope & $-4.3 \pm 0.52$ & $-5.3 \pm 0.62$ & $-5.3 \pm 0.95$ \\
$\varepsilon_{6}\left[10^{-6}\right]$ & 168 & 156 & 132
\end{tabular}

Confidence interval $\left[10^{-6}\right] \quad 162<\varepsilon_{6}<173 \quad 151<\varepsilon_{6}<162 \quad 122<\varepsilon_{6}<142$

Some trends on the $\varepsilon_{6}$ and the $p$ values can be pointed out.

The fatigue slope $p$ is not clearly dependant on the size taking the scattering and the confidence interval into account. However, in previous works (Bodin, 2002) it had been shown that the fatigue slope is dependant on the viscoelasticity induced self heating under sinusoidal loading. That remark should induce an increase of the slope with the specimen size. The small difference in slope between the small size 0.5 and the medium size 1.0 is in accordance with that previous remark.

The value $\varepsilon_{6}$ appears to be a function of the specimen size. It decreases with the size. The confidence interval increases with the size, however the difference between the three $\varepsilon_{6}$ value is significative. This last observation is really important if the value is used as a design limit of the maximal strain in the pavement layer. For the same 
material, a decrease of the $\varepsilon_{6}$ value will induced an increase of the thickness necessary to keep the extension at the base of the layer below this fatigue limit. It is well known that $\varepsilon_{6}$ is not an intrinsic parameter and depends on the specimen shape used for the laboratory fatigue test. However it is also shown here that it is dependant on the size of the sample even if the samples are geometrically similar. The $\varepsilon_{6}$ value does not lead to an intrinsic evaluation of the material fatigue resistance of asphalt mixes.

These global results follow the trends of the structure resistance decrease with the size of the specimen which is qualitatively in accordance with the classical size effects results (Bažant, 2002).

This direct interpretation of the fatigue results points out the dependence on the specimen size. But if we want to consider the whole problem we have to consider the viscoelasticity induced self heating of the material which is, regarding to cracking, a biased effect but which leads to a thermal size effect. This last one is finally totally coupled in the whole laboratory fatigue phenomenon.

\section{Mechanical modelling}

An elasticity based damage approach has been used to describe the local complex modulus decrease induced by microcrack development (Bodin et al., 2004b; Bodin, 2002). In the description of the whole fracture process, the strain localization phenomenon is treated by a non local damage model (Pijaudier-Cabot et al., 1987). A 3D finite element implementation has been carried out for structural fatigue calculations using a cycle based time integration scheme.

\subsection{Brief summary of the equations}

In the complex strain-stress law (equation 2), where $\sigma_{i j}$ and $\varepsilon_{k l}$ are respectively the elastic stress and strain tensor components, the influence of micro-cracking is introduced via a single scalar damage variable $D$. It grows from 0 for the virgin material to 1 when the material does not transfer stress anymore. This damage variable $D$ affects the material isotropic modulus tensor $C_{i j k l}$, function of the Young modulus $E$ and the Poisson ratio $\nu$.

$$
\sigma_{i j}=(1-D) C_{i j k l} \varepsilon_{k l}
$$

According to the French pavement design method, $\nu$ is assumed to be a constant equal to 0.35 . The value of the Young modulus $E$ is taken as the value of the complex modulus at the given temperature and frequency of the test (here $10^{\circ} \mathrm{C}$ and $10 \mathrm{~Hz}$ ).

The model used to describe the mechanical weakening due to material micro cracking is an elasticity based damage model for fatigue. The elasticity framework is applied to the complex modulus and matches the viscoelastic formalism for sinusoidal 
loading with an offset equal to zero. Evolution of damage is controlled by the strain state of the material by a scalar equivalent strain. The strains induced by positive principal stresses $\sigma_{i}$ are assumed to lead to the damage growth as follows:

$$
\tilde{\varepsilon}=\sqrt{\sum_{i=1, \ldots, 3} \frac{<\sigma_{i}>^{2}}{E(1-D)}} \text { where } \quad<x>=\frac{1}{2}(|x|+x)
$$

where $E$ is the Young modulus of the virgin material.

For structural computation, the non-local enhancement of the presented model is used. It consists in replacing the equivalent strain value by the weighted average of the local equivalent strain taken over a region about the considered point: the non-local equivalent strain as follow:

$$
\bar{\varepsilon}=\frac{1}{V_{r}(x)} \int_{\Omega} \Psi(x-s) \tilde{\varepsilon}(s) d s \quad \text { avec } \quad V_{r}(x)=\int_{\Omega} \Psi(x-s) d s
$$

where $\Omega$ is the volume of the structure, $V_{r}(x)$ is the representative volume at point $x$ and $\Psi$ is the weight function chosen as a gaussian function

$$
\Psi(x-s)=\exp -\frac{4\|x-s\|^{2}}{l_{c}^{2}}
$$

The characteristic length $l_{c}$ is the internal length of the non local continuum. It is related to the microstructure of the material. It controls the size of damage localization zone. For cement concrete, its value is given as a function of the maximal aggregate size of the mix (Bažant et al., 1989).

For bituminous material, it has not yet being carefully determined but, according to experimental data, its value is fixed to three times the maximum aggregate size of the mix according to results on cementitious concrete. When the strain state is homogeneous over the specimen, like in uniaxial tension or compression, the non local equivalent strain (Eq. 4) is equal to the local equivalent strain (Eq. 3).

The rate of damage growth is defined as a function of this nonlocal equivalent strain rate (Mazars et al., 1989):

$$
\dot{D}=f(D) \bar{\varepsilon}^{\beta}<\dot{\bar{\varepsilon}}>
$$

$f(D)$ is a function of damage which is defined later on. The exponent $\beta$ is a model parameter. It is supposed to be a material parameter and it can be demonstrated that 
$-(\beta+1)$ corresponds to the slope of the Wöhler curve in the log-log diagram. Its value can be easily fitted on experimental data.

The three stage damage evolution law is given by Eq. 7 .

$$
f(D)=\frac{\alpha_{2}}{\alpha_{1} \alpha_{3}}\left(\frac{D}{\alpha_{2}}\right)^{1-\alpha_{3}} \exp \left(\frac{D}{\alpha_{2}}\right)^{\alpha_{3}}
$$

$\alpha_{1}, \alpha_{2}$ and $\alpha_{2}$ are material parameters fitted on experimental data. This mathematical form is expressed as the product of two different terms. The first one is a power law factor. The second one leads to the phase II phase III transition.

The model is implemented in the finite element code Cast3M coupled to a jump in cycle procedure to perform high cycle fatigue simulation without calculation of each cycle. The meshes and the time algorithm parameters had been fixed according to (Bodin, 2002).

\subsection{Size effect of the damage model}

Fatigue test are simulated under isothermal assumption to estimate the size effect according to the nonlocal fatigue damage model.

Model parameters are fixed to the values evaluated in (Bodin, 2002) for similar material but manufactured with a different $50 / 70$ binder from the same origin. The $\varepsilon_{6}$ for this material was $15210^{-6}$ to be compared with $15610^{-6}$ here (Tab. 2). The small difference in $\varepsilon_{6}$ can be explained by the lower void content of the present material (3.2\% (figure 3(b)) to be compared to $5 \%$ for the previous one) which leads to an increase of $\varepsilon_{6}$ around $310^{-6}$ per one percent void content (Moutier, 1991).

This void contents difference leads to an expected increase of fatigue life for the present material regarding the previous study. This trend is confirmed further by figures 9 where the model leads to predictions with shorter fatigue lifes.

Three parameter sets have been fitted to take into account the experimental scattering of experimental fatigue. They are gathered in the table 3 where the mean parameter set had been fitted considering the average experimental data. The maxi and the mini parameters set had been fitted on extreme experimental data obtained during this previous work (Bodin, 2002). This method allows to estimate the consequences of the scatter of experimental data on fatigue predictions as shown in figure 8 .

The effect of the size is illustrated on the stiffness decrease curves. The figure 8 shows the results simulated at a loading level of $14010^{-6}$.

The size effect of the non local damage model is characterized by different stiffness decrease curve for each specimen size. Compared to the standard size $(\operatorname{size}=1)$, the figure (8) shows that the stiffness decrease is faster for big samples $($ size $=2$ ) and 
Table 3. Parameters of the non local damage growth law (Bodin, 2002)

\begin{tabular}{cccccc}
\hline & \multicolumn{3}{c}{ Model parameters } & \multicolumn{2}{c}{ Characteristic length } \\
\hline & $\beta$ & $\alpha_{1}$ & $\alpha_{2}$ & $\alpha_{5}$ & $l c[\mathrm{~m}]$ \\
maxi & 4.0 & $7.7410^{-15}$ & 0.42 & 3.0 & $1810^{-3}$ \\
mean & 4.0 & $5.5810^{-15}$ & 0.42 & 3.0 & $1810^{-3}$ \\
mini & 4.0 & $5.1210^{-15}$ & 0.46 & 3.09 & $1810^{-3}$ \\
\hline
\end{tabular}

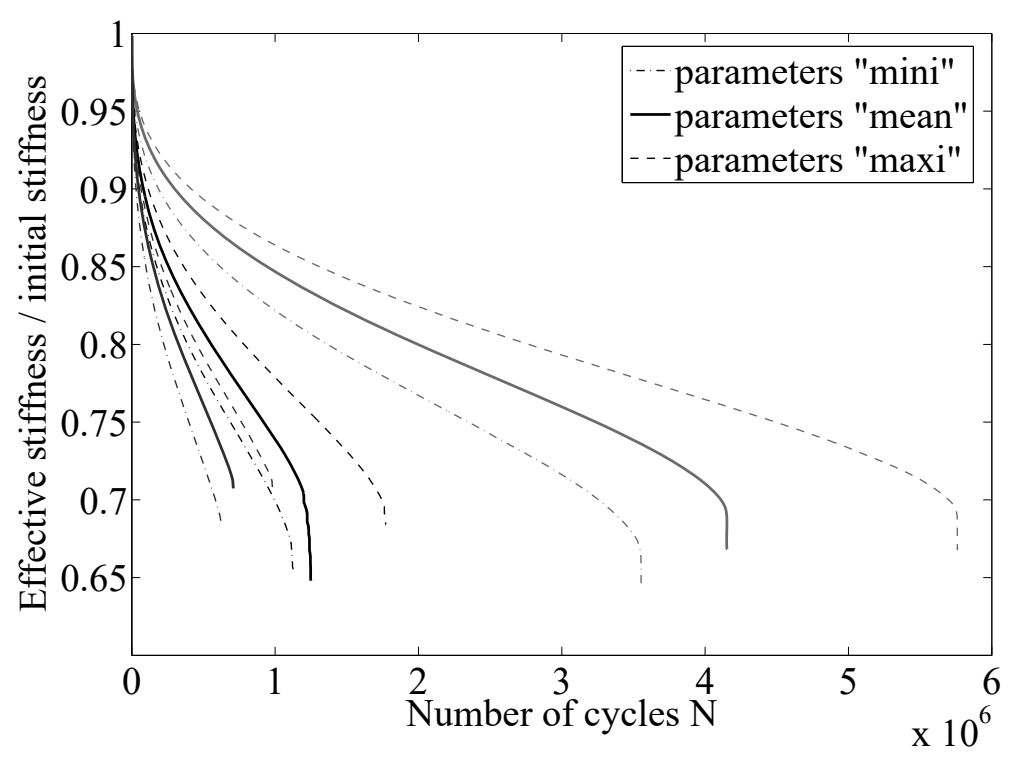

Figure 8. Simulated stiffness decrease calculated with the damage model elaborated and fitted (Bodin, 2002) for the loading level $14010^{-6}$ for the three parameters set (Tab. 3)

slower for small samples $($ size $=0.5)$. As a consequence, the fatigue life decreases with an increase in the size of the considered specimen.

This qualitative trends are in accordance with the experimental results shown in the figures 5. It has to be pointed out that the mini and maxi range for size 1.0 and 2.0 also lead to overlapping predictions. We will now compare this size effect to experimental data.

\subsection{Comparison between model and experiments}

The first stage consists in comparing fatigue prediction for the standard size used for the original modelling. Then, from this reference size, simulations of fatigue tests on the two other sizes will be compared to experimental results. 


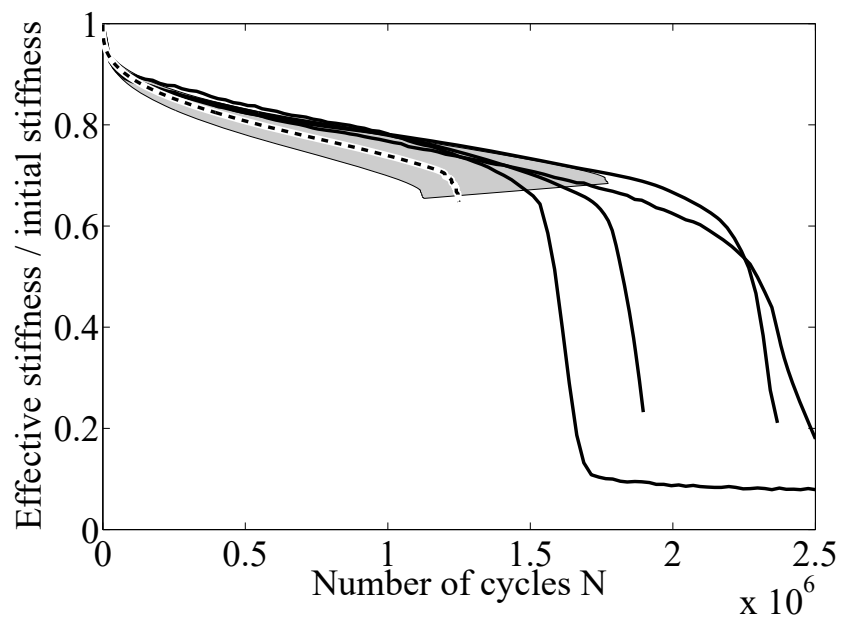

(a)

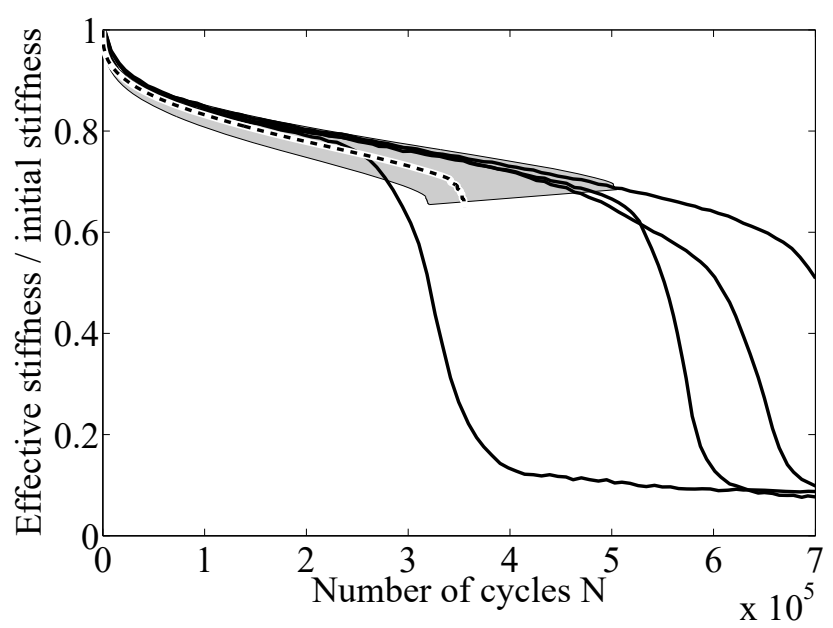

(b)

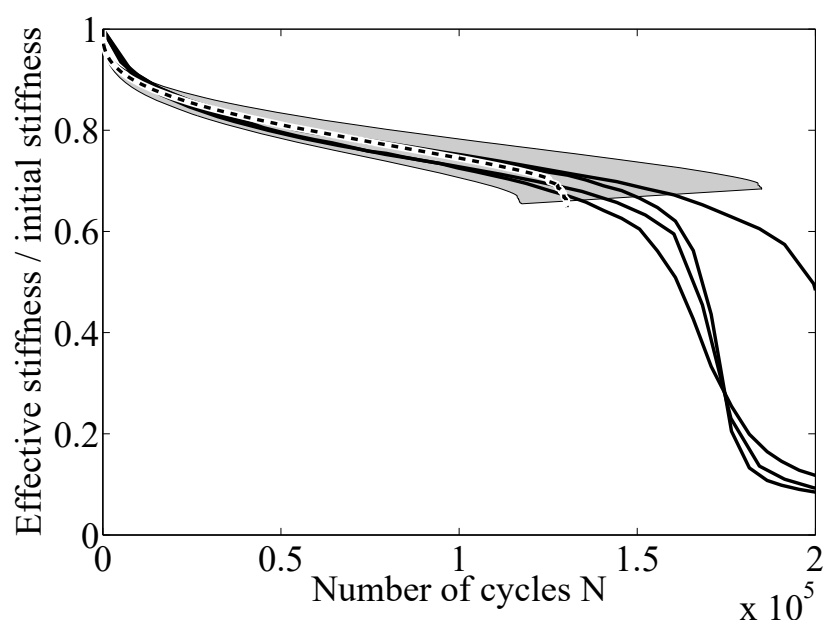

(c)

Figure 9. Comparison of the model prediction with experimental data for the standard specimen size 1.0 for the three loading levels : (a) level $14010^{-6}$, (b) level $18010^{-6}$ and (c) level $22010^{-6}$ 


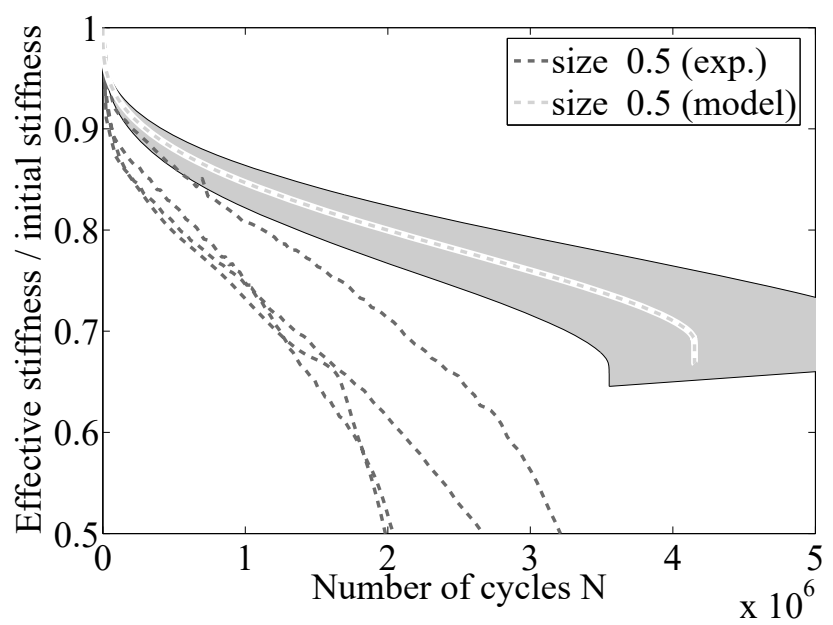

(a)

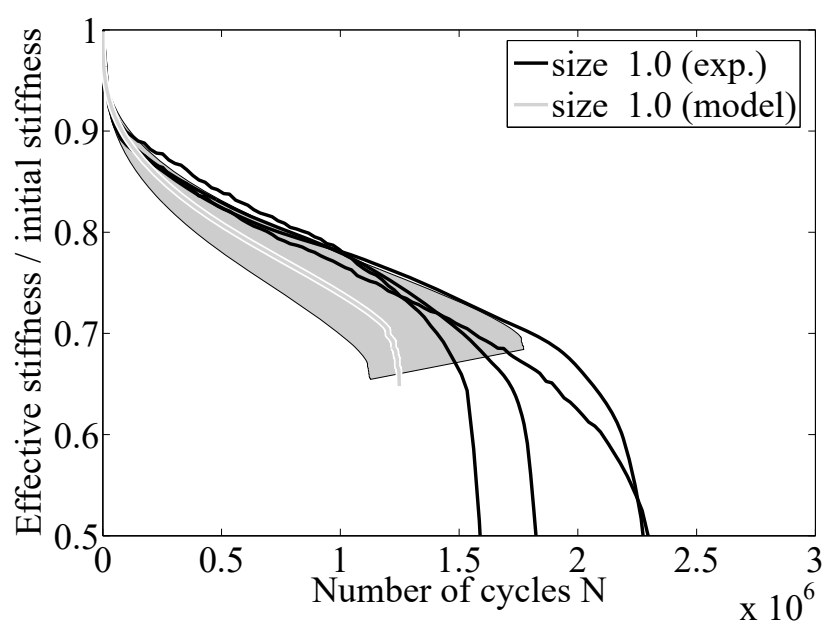

(b)

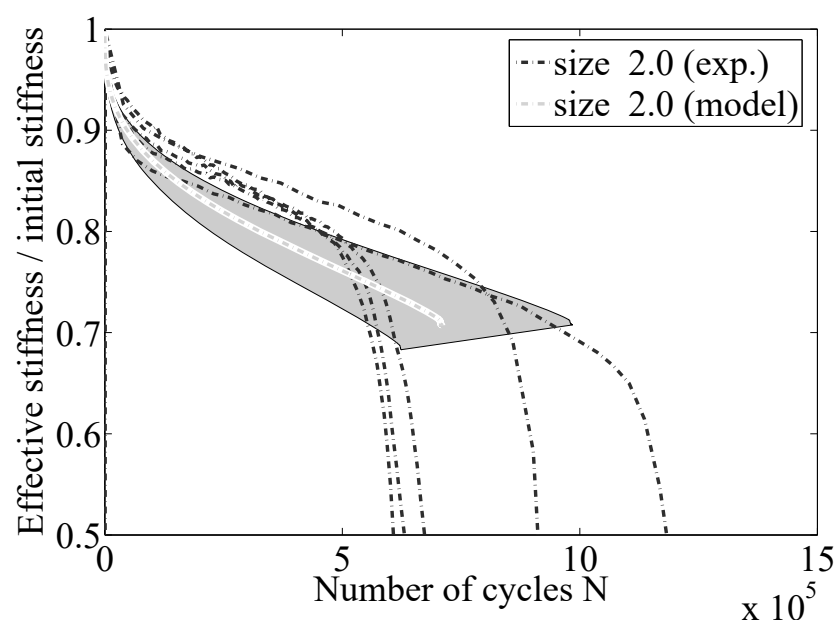

(c)

Figure 10. Comparison of the model prediction with experimental data for the standard specimen for the three specimen series for the $14010^{-6}$ loading level : (a) size 0.5 , (b) size 1.0 and (c) size 2.0 with a visualization of the grey prediction zone according to Tab. (3). 


\subsubsection{Comparison for size 1.0}

Before the comparison of the fatigue prediction for the different size, the fatigue prediction has been evaluated on the standard size (size 1.0) in order to see if the model fitted during another study is still predictive for the present asphalt mixture differing only on the binder year of fabrication and the compaction protocol. Figures 9 present the superposition of size effect experimental data for the three loading levels with the prediction of the nonlocal fatigue damage model. The green line are the prediction of the model using the average parameter set (Tab. 3) and the prediction zone in grey is bounded by the predictions using the two maxi and mini parameter sets.

The model allows an acceptable prediction of the experimental data, even if a light systematic difference leads to an earlier failure for the model which can be due to material compacity difference as explained earlier. In consideration of this, model predictions are close to experimental measurements, what allows to compare the trends of modelling size effects compared to experimental observations.

\subsubsection{Model size effect compared to experimental data}

On figures 10 nonlocal fatigue damage simulations are plotted in green superimposed to experimental data for the three tested sizes. To stay closer to the isothermal assumption, only the lowest loading level $\left(14010^{-6}\right)$ is presented.

Considering size 1.0, results are the same than on figure 9(a). The two dotted green lines are plotted with simulated data for the sizes 0.5 and 2.0.

We observe that fatigue life is well predicted for the size 2.0 and the distance between model and experiment grows with the decreasing of the size. For the smallest size, the model predicts a failure for a larger number of cycles than it is observed in the lab. This trend on the lowest level is confirmed on fatigue lines presented in the next section.

\subsubsection{Size effect on fatigue line}

To achieve the study of comparison between the nonlocal fatigue model and experimental results the comparison of Wöhler curves for the three size allows to summarize the differences between model prediction and experimental data.

Figure 11 illustrates the model fatigue lines with a visualization of the prediction zone (three sets of model parameters given table 3 ) given by the errorbars for the three loading levels.

Model agreement is better for large samples with a fatigue line very close to experimental data. For the other sizes the differences between model and experimental data grows with the decreasing of the size. However for the size 1.0 experimental data are included in the model prediction zone. For size 0.5 the model leads to a systematic overevaluation of the fatigue life. 


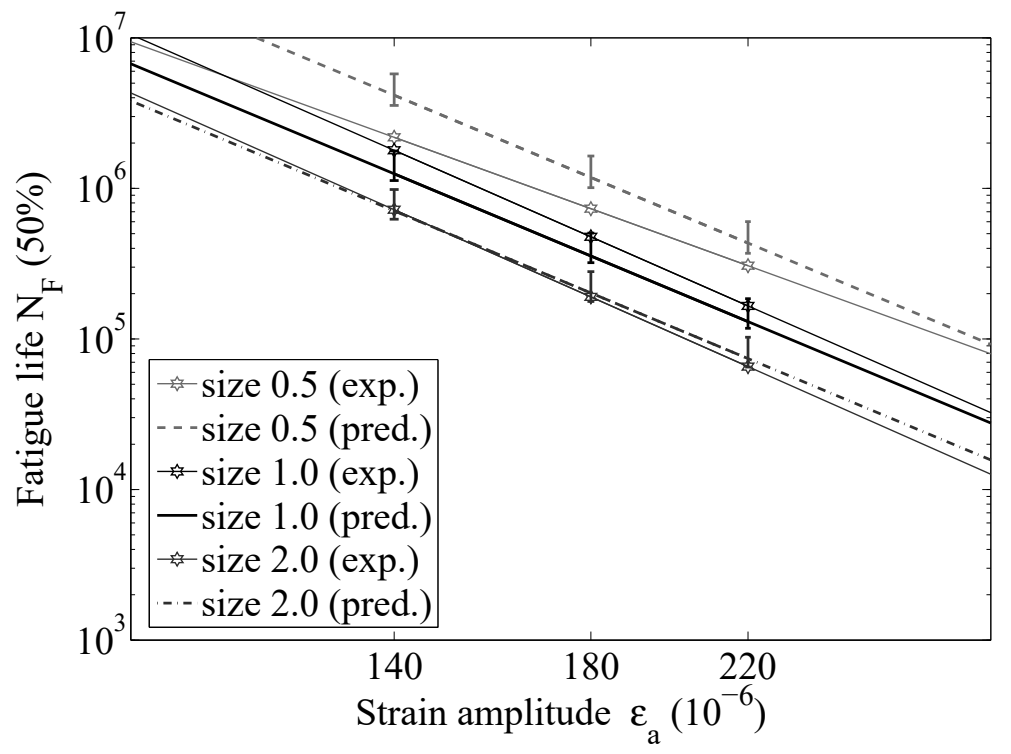

Figure 11. Comparison of model predictions (pred.) and experiment (exp.) fatigue line for each size.

At this stage and before going further in the analysis, these observations have to be enlightened by the consequences of the model assumption. The following discussion highlights effects of neglecting thermal softening and the consequence of the internal length choice.

\subsubsection{Discussion and prospects on the model size effect}

Viscoelastic dissipation and the material softening due to thermal increase may affect the fatigue response. As reported for tension compression test on cylinder which exhibit large thermal effect due to the shape of the specimen (Bodin et al., 2004a), the fatigue life may be affected by the coupling between damage and thermal softening. The effect is neglectible for low loading levels but, in this case may decrease the fatigue of more than $50 \%$ for high loading levels.

This effect also exists for bending test even if its effect is lower due to the test geometry. Nevertheless, the evaluation of this complex phenomenon needs to solve the completely transient thermomechanical problem coupled with damage.

Nevertheless, an estimation of the expected thermal effect can be calculated according to numerical modelling (de La Roche et al., 1998; Bodin, 2002). For displacement controlled test and without damage, the balance between dissipated energy and exchanges through the specimen boundaries leads to a permanent state. For this state the temperature field in the specimen leads to a global stiffness decrease. The relative stiffness decrease in percent characterize this thermal effect. For all the tested conditions simulation results are gathered in table 4 . 
Table 4. Maximum stiffness decrease [\%] due to self heating estimation without damage coupling

\begin{tabular}{lccc}
\hline level $\left[10^{-6}\right]$ & \multicolumn{3}{c}{ Size } \\
& 0.8 & 1.8 & 3.7 \\
\hline 140 & 1.1 & 1 & 0.42 \\
180 & 1.4 & 2.9 & 6.1 \\
220 & 2.1 & 4.4 & 9.3 \\
\hline
\end{tabular}

The global stiffness decrease induced by the viscoelastic selfheating during sinusoidal loadings is between less than $1 \%$ and near $10 \%$. For small samples (size 0.5 ) tested with low level loading the thermal effect can be neglectible. But for the largest samples (size 2.0) tested with high level loading the thermal effect can be coupled to the damage growth process.

However, without thermal coupling the model gives a qualitative respect. But, it had to be pointed out that the model does not capture quantitatively the size effect given back by experiments. This can be due to the characteristic length value $l_{c}$ which had not been identified yet for asphalt mixtures even if some image analysis method seems to be very hopeful (Seo et al., 2004).

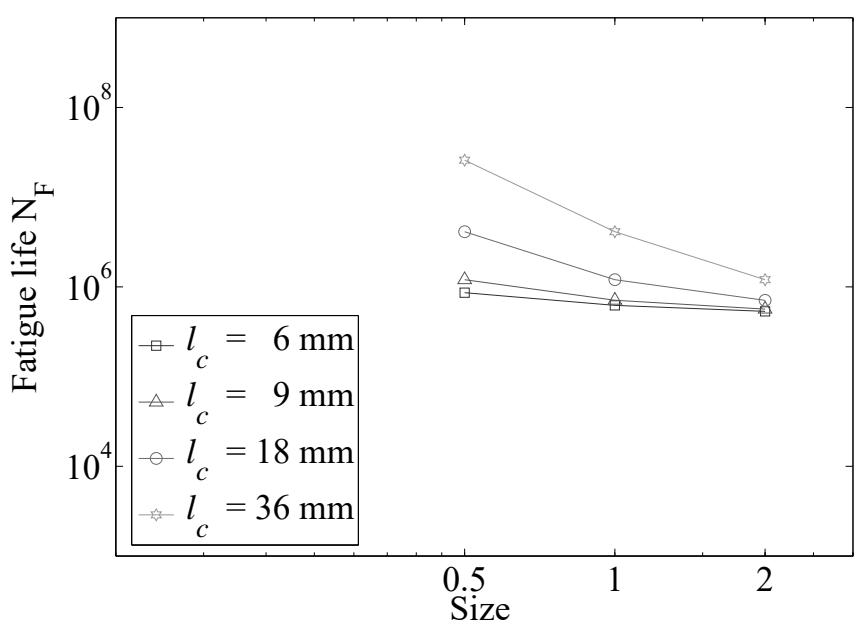

(a)

\begin{tabular}{lccc}
\hline$l_{c}\left[10^{-3} \mathrm{~m}\right]$ & \multicolumn{3}{c}{ Size } \\
& 0.5 & 1.0 & 2.0 \\
\hline 6 & 1.4 & 1 & 0.86 \\
12 & 1.7 & 1 & 0.80 \\
$\mathbf{1 8}$ & $\mathbf{3 . 4}$ & $\mathbf{1}$ & $\mathbf{0 . 5 9}$ \\
36 & 6.3 & 1 & 0.29 \\
\hline
\end{tabular}

(b)

Figure 12. Size effect of the model function of the characteristic length $l_{c}$ (a) Effect of the specimen size on the fatigue life (b) ratio of fatigue life for each size $i$ to fatigue life for the reference size 1. for each characteristic length

The comparison between figure 12(a) and figure 6(a) shows that the model reduces the fatigue drop for the change of geometry from size 1.0 to size 2.0 and increases the fatigue drop for the change of geometry from size 0.5 to size 1.0. To stay in the isothermal conditions where thermal effects are the lowest (small sizes and small 
levels) better agreement between the model size effect and experimental size effect should be obtained for characteristic length $l_{c}$ lower than $18 \mathrm{~mm}$ chosen according cementitious concrete under monotonic loadings. However for small values of $l_{c}$ the size effect between size 1.0 and size 2.0 will be lower than experimental data. Nevertheless, for size 2.0 samples thermal effects are greater and may lead to premature failure which are not captured in isothermal conditions.

Without any quantification, we can conclude that effect of the characteristic length is important. Experimental results leads us to suppose that its value is smaller than three time the maximal aggregate size if thermal effects are correctly taken into account in the analysis.

\section{Conclusion}

The study of the influence of the cantilever beam size in bending fatigue shows the effect of the size on fatigue characterization of asphalt mixes. Tested specimen are geometrically similar, and for specimen tested at the same loading level, the stiffness decrease vs the number of cycles is faster when the size is bigger. In terms of fatigue life : the biggest the sample, the shortest the fatigue life (number of cycles to failure).

The nonlocal fatigue damage model leads to a dependency of the fatigue results with the specimen size. For the model, the fatigue life decreases with the increasing of the specimen size. These qualitative trends are conform to size effect experimental results. To extend the conclusions, the thermal softening due to viscolestacity induced heating need to be considered coupled to the damage process. Future size effects studies should give a way to calibrate the characteristic length $l_{c}$ using an inverse fitting method like it has been achieve for cementitious concrete (Bellégo et al., 2003).

These results highlight once again that even if fatigue damage is intrinsic considered at the material local scale, fatigue tests results strongly depend on the sample geometry and its size even if tested specimens are geometrically similar.

If the size effect is confirmed by other studies, a practical outcome is conceivable to evaluate fatigue performances on smaller specimens sawn from cores extracted from pavements

\section{Bibliography}

Bažant Z. P., Scaling of Structural Strength, Hermes Penton Science, London, 2002.

Bažant Z. P., Pijaudier-Cabot G., " Measurement of Characteristic Length of Nonlocal Continuum”, Journal of Engineering Mechanics, Vol. 115, No 4, p. 755-767, april, 1989.

Bažant Z. P., Xu K., “ Size effect in fatigue of concrete”, ACI Material Journal, Vol. 88, No 4, p. 390-399, july-august, 1991.

Bellégo C. L., Dubé J.-F., Cabot G. P., Gérard B., " Calibration of Non Local Model from size effects Tests”, European Journal of Mechanics - A/Solids, Vol. 22, No 1, p. 33-46, 2003. 
Benedetto H. D., de La Roche C., Baaj H., Pronk A., Lundstrom R., " Fatigue of bituminous mixtures : Different approches and Rilem group contribution", proceedings of the $6^{\text {th }}$ International RILEM Symposium on Performance Testing and Evaluation of Bituminous Materials, Zurich, Switzerland, 14-16 April, 2003.

Bodin D., Modèle d'endommagement par fatigue : Application aux enrobés bitumineux, Thèse de doctorat, École Centrale de Nantes, Nantes, France, Décembre, 2002.

Bodin D., Belzung F., de La Roche C., Chabot A., “ Thermomechanical modelling for fatigue damage of bituminous materials", proceedings of the $5^{\text {th }}$ International RILEM Conference - Cracking in Pavements, Limoge, France, 5-7 May, 2004a.

Bodin D., Pijaudier-Cabot G., de La Roche C., Piau J.-M., Chabot A., “ A continuum damage approach to asphalt concrete fatigue Modelling”, Journal of Engineering Mechanics, ASCE, Vol. 130, No 6, p. 700-708, June, 2004b.

Carpinteri A., Spagnoli A., “A fractal analysis of size effect on fatigue crack growth", International Journal of Fatigue, Vol. 26, No 2, p. 125-133, 2004.

da Vinci L., Les manuscrits de Léonard de Vinci, vol. 3, transl. in French by C. RavaissonMollien, Institut de France, Paris, 1881-91.

de La Roche C., Module de rigidité et comportement en fatigue des enrobés bitumineux. Expérimentations et nouvelles perspectives d'analyse., Thèse de doctorat, Ecole Centrale Paris, Paris - France, novembre, 1996.

de La Roche C., Piau J.-M., Dangla P., “ Thermal effects induced by viscoelastic dissipation during fatigue tests on bituminous mixtures", Proceedings of the $6^{\text {th }}$ International Symposium On Creep and Coupled Process - sept. 23-25, Bialowieza, Poland, 1998.

Doan T. H., Recherche en fatigue des enrobés bitumineux, Document interne, L.C.P.C., 1973.

Galileo G. L., Discorsi i Demonstrazioni Matematiche intorno à due Nuovo Science, 1638.

Lundstrom R., Benedetto H. D., Isacsson U., " Influence of Asphalt Mixture Stiffness on Fatigue Failure”, Journal of Material in Civil Engineering, Vol. 16, No 6, p. 516-525, december, 2004.

Mazars J., Pijaudier-Cabot G., “Continuum damage theory - Application to concrete”, International Journal of Engineering mechanics, Vol. 115, No 2, p. 345-365, february, 1989.

Moutier F., "Étude statistique de l'effet de la composition des enrobés bitumineux sur leur comportement en fatigue et leur module complexe", Bulletin de Liaison des Laboratoires des Ponts et Chaussées, Vol. 172, p. 71-79, 1991.

Pijaudier-Cabot G., Bažant Z. P., “ Nonlocal damage theory”, Journal of Engineering Mechanics, Vol. 113, No 10, p. 1512-1533, oct., 1987.

Seo Y., Kim Y. R., " The mechanical testing of asphalt concrete mixtures using digital iamge correlations", proceedings of the $5^{\text {th }}$ International RILEM Conference - Cracking in Pavements, Limoge, France, 5-7 May, 2004.

SHRP C., Fatigue Response of Asphalt Aggregate Mixes, Strategic Highway Research Program (SHRP), Washington, D.C. 1994.

Tomassone R., Audrain S., de Turckheim E. L., Millier C., La régression - Méthode statistique, Masson - Actualités INRA, Paris, 1992. 